\title{
ORGANOGENESIS AND EMBRYOGENESIS IN SEVERAL HYPERICUM PERFORATUM GENOTYPES
}

\author{
G. FRANKLIN AND A. C. P. DIAS* \\ Departamento de Biologia, Universidade do Minho, Campus de Gualtar, 4710-057 Braga, Portugal
}

(Received 22 August 2005; accepted 16 May 2006; editor P. J. Weathers)

\section{SUMMARY}

St John's wort (Hypericum perforatum) is a valuable plant used as a herbal remedy or in phytopharmaceutical drugs to treat a variety of physical ailments. Much research has been performed to study the biochemical production of secondary metabolites of in vitro cultured plants or organs. However, all of these studies have looked at the regeneration of plants from explants in only one genotype. In addition, no study has revealed the mechanism of plant regeneration in H. perforatum, i.e. organogenesis or somatic embryogenesis. We found that different genotypes Helos, Topas, Elixir, and Numi responded similarly to regeneration medium. The regeneration responses (i.e. callus, root, or shoot production) of identical explants from different genotypes were similar. However, the source of explant material (leaves, hypocotyls, and roots) from the same genotype had significant effects on the response to media and plant regeneration frequency. Using scanning electron microscopy and light microscopy, the progress of organogenesis and embryogenesis under similar culture conditions was recorded. Root segments were the most responsive explants, producing the maximum number of shoots per explant of all the genotypes.

Key words: Embryogenesis; genotype; hypericum perforatum; organogenesis; St John's wort.

INTRODUCTION

Hypericum perforatum L. (St John's wort) is a well-known traditional medicinal plant distributed globally. Extracts from this plant have been proven to have important pharmaceutical effects, including anti-viral activity (Schinazi et al., 1990), anti-cancer activity (Agostinis et al., 2002), anti-depressant activity (Butterweck, 2003), and anti-oxidant activity (Silva et al., 2005). Presently, $H$. perforatum is one of the top-selling medicines worldwide. St John's wort products are presently sold in the USA as a dietary supplement, while in EU countries, these products are sold as anti-depressive agents, relaxants, and mood enhancers (Gibson and Sirvent, 2002).

Due to the potential for value-added properties from H. perforatum, in vitro regeneration of plants has been investigated as an option for multiplication of elite plants and production of valuable phytopharmaceuticals. Although in vitro regeneration of St John's wort has been achieved from several types of explants, these studies were restricted either to single genotypes (Murch et al., 2000; Pretto and Santarem, 2000; Zobayed and Saxena, 2003; Zobayed et al., 2004) or to the production of secondary metabolites in cell cultures and regenerated plants (Kirakosyan et al., 2000; Dias et al., 2001; Smith et al., 2002; Dias and Ferreira, 2003; Pasqua et al., 2003).

In spite of several reports on plant regeneration of $H$. perforatum, current understanding of the regeneration pathways is limited, since most of these reports neglect to reveal the mode of plant regeneration. Elucidation of the pathway of plant regeneration will

*Author to whom correspondence should be addressed: Email acpdias@ bio.uminho.pt contribute to the synchronous development of shoots for commercial propagation and identify the precise target cells or tissues for genetic transformation. Hence, the present investigation was designed with two objectives: to establish a genotype-independent plant regeneration protocol and to elucidate the specific pathway of plant regeneration in $H$. perforatum.

\section{Materials and Methods}

Genotypes and seed source. Four genotypes representing a wider range of $H$. perforatum cultivars were selected for the present study, including Helos, a fungal tolerant cultivar; Topas, a genotype consistent in phytochemical production and used as the standard for the production of phytopharmaceuticals; Elixir, a genotype with high hypericin content; and Numi, a wildtype genotype collected in Braga (north of Portugal). Helos, Topas, and Elixir seeds were purchased from Richters Seeds (Ontario, Canada).

Aseptic seed germination and explant preparation. Seeds of $H$. perforatum genotypes were separately placed in $2.0 \mathrm{ml}$ Eppendorf tubes containing $1.0 \mathrm{ml}$ sterile water and a drop of Tween 20 and kept in the dark at $4^{\circ} \mathrm{C}$. After $12 \mathrm{~h}$, the solution was removed and the seeds were surface sterilized with $70 \%$ ethyl alcohol for $60 \mathrm{~s}$ followed by commercial bleach $(1.5 \%$ active chlorine) for $3 \mathrm{~min}$, and then washed three times in sterilized distilled water. After blotting on a sterile filter paper, the seeds were transferred onto wateragar $(0.8 \%$ agar, w/v) medium for germination. Seedlings were transplanted to baby food jars (V0633, Sigma, Barcelona, Spain) containing $50 \mathrm{ml}$ of halfstrength MS basal medium (Murashige and Skoog, 1962) supplemented with $1.5 \%$ sucrose $(\mathrm{w} / \mathrm{v})$ after $10-15 \mathrm{~d}$ for further growth. Various plant parts, such as leaves, hypocotyls, and root segments excised from the aseptic seedling, were used as explants.

Optimization of plant regeneration. Effects of plant growth regulator (PGR) combinations on regeneration were studied by culturing explants obtained from cultivar. Helos on MS medium containing different concentrations of 6-benzylaminopurine (BA) either alone or in combination with indole-3-acetic acid (IAA) (M1-M20, Table 1). Combination of $3 \%$ $(\mathrm{w} / \mathrm{v})$ sucrose and $0.8 \%(\mathrm{w} / \mathrm{v})$ agar was common to all media. The medium $\mathrm{pH}$ 
TABLE 1

REGENERATION RESPONSE OF ST JOHN'S WORT (HELOS) EXPLANTS ON VARIOUS PGR COMBINATIONS

\begin{tabular}{|c|c|c|c|c|c|}
\hline \multirow[b]{2}{*}{ Media code } & \multirow[b]{2}{*}{$\mathrm{BA}(\mu M)$} & \multirow[b]{2}{*}{ IAA $(\mu M)$} & \multicolumn{3}{|c|}{ Regeneration response } \\
\hline & & & Root & Leaf & Hypocotyl \\
\hline M1 & 0.0 & 0.0 & $\mathrm{~N}(2.0 \pm 0.7) \mathrm{b}$ & $\mathrm{N}(0 \pm 0) \mathrm{a}$ & $\mathrm{N}(0 \pm 0) \mathrm{a}$ \\
\hline M2 & 0.44 & 0.0 & $\mathrm{~S}(6.4 \pm 3.7 \mathrm{a}) \mathrm{b}$ & $\mathrm{N}(0 \pm 0) \mathrm{a}$ & $\mathrm{S}(3.3 \pm 1.5 \mathrm{a}) \mathrm{b}$ \\
\hline M3 & 2.2 & 0.0 & $\mathrm{~S}(22.0 \pm 7.7 \mathrm{bc}) \mathrm{b}$ & $\mathrm{S}(20.3 \pm 6.4 \mathrm{c}) \mathrm{b}$ & $\mathrm{S}(9.4 \pm 1.9 \mathrm{~b}) \mathrm{a}$ \\
\hline M4 & 4.4 & 0.0 & $\mathrm{~S}(0 \pm 0) \mathrm{a}$ & $\mathrm{S}(8.7 \pm 3.5 \mathrm{~b}) \mathrm{b}$ & $\mathrm{S}(12.0 \pm 3.2 \mathrm{bc}) \mathrm{b}$ \\
\hline M5 & 8.8 & 0.0 & $\mathrm{~N}(0 \pm 0) \mathrm{a}$ & $\mathrm{N}(0 \pm 0) \mathrm{a}$ & $\mathrm{N}(0 \pm 0) \mathrm{a}$ \\
\hline M7 & 0.44 & 0.57 & $\mathrm{~S}(9.3 \pm 3.9 \mathrm{a}) \mathrm{a}$ & $\mathrm{S}(8.5 \pm 2.1 \mathrm{~b}) \mathrm{a}$ & $\mathrm{S}(10.4 \pm 4.0 \mathrm{bc}) \mathrm{a}$ \\
\hline M8 & 2.2 & 0.57 & $\mathrm{~S}(20.8 \pm 9.4 \mathrm{bc}) \mathrm{a}$ & $\mathrm{S}(14.3 \pm 1.5 \mathrm{bc}) \mathrm{a}$ & $\mathrm{S}(13.6 \pm 3.6 \mathrm{bc}) \mathrm{a}$ \\
\hline M9 & 4.4 & 0.57 & $\mathrm{~S}(16 \pm 3.7 \mathrm{~b}) \mathrm{b}$ & $\mathrm{S}(8.7 \pm 2.1 \mathrm{~b}) \mathrm{a}$ & $\mathrm{S}(14.0 \pm 4.7 \mathrm{bc}) \mathrm{ab}$ \\
\hline M10 & 8.8 & 0.57 & $\mathrm{~N}(0 \pm 0) \mathrm{a}$ & $\mathrm{N}(0 \pm 0) \mathrm{a}$ & $\mathrm{N}(0 \pm 0) \mathrm{a}$ \\
\hline M11 & 0.0 & 2.85 & $\mathrm{R}(0 \pm 0) \mathrm{a}$ & $\mathrm{N}(0 \pm 0) \mathrm{a}$ & $\mathrm{N}(0 \pm 0) \mathrm{a}$ \\
\hline M12 & 0.44 & 2.85 & $\mathrm{~S}(13.7 \pm 8.1 \mathrm{ab}) \mathrm{b}$ & $\mathrm{S}(4.0 \pm 1.0 \mathrm{a}) \mathrm{a}$ & $\mathrm{S}(9.2 \pm 2.7 \mathrm{~b}) \mathrm{b}$ \\
\hline M13 & 2.2 & 2.85 & $\mathrm{~S}(33.4 \pm 5.7 \mathrm{c}) \mathrm{c}$ & $\mathrm{S}(11.9 \pm 2.2 \mathrm{bc}) \mathrm{b}$ & $\mathrm{S}(4.5 \pm 1.4 \mathrm{a}) \mathrm{a}$ \\
\hline M14 & 4.4 & 2.85 & $\mathrm{~S}(18.1 \pm 4.3 \mathrm{~b}) \mathrm{a}$ & $\mathrm{S}(12.3 \pm 1.9 \mathrm{bc}) \mathrm{a}$ & $\mathrm{S}(10.0 \pm 4.1 \mathrm{~b}) \mathrm{a}$ \\
\hline M17 & 0.44 & 5.7 & $\mathrm{~S}(12.5 \pm 6.5 \mathrm{ab}) \mathrm{a}$ & $\mathrm{S}(8.7 \pm 1.5 \mathrm{~b}) \mathrm{a}$ & $\mathrm{S}(10.3 \pm 2.2 \mathrm{~b}) \mathrm{a}$ \\
\hline M18 & 2.2 & 5.7 & $\mathrm{~S}(26.1 \pm 3.7 \mathrm{bc}) \mathrm{b}$ & $\mathrm{S}(16.0 \pm 4.3 \mathrm{bc}) \mathrm{a}$ & $\mathrm{S}(16.9 \pm 2.4 \mathrm{c}) \mathrm{a}$ \\
\hline M19 & 4.4 & 5.7 & $\mathrm{~S}(20.5 \pm 2.9 \mathrm{~b}) \mathrm{b}$ & $\mathrm{S}(13.8 \pm 3.0 \mathrm{bc}) \mathrm{a}$ & $\mathrm{S}(14.5 \pm 3.1 \mathrm{bc}) \mathrm{ab}$ \\
\hline M20 & 8.8 & 5.7 & $\mathrm{~S}(18.4 \pm 3.8 \mathrm{~b}) \mathrm{b}$ & $\mathrm{S}(11.75 \pm 3.0 \mathrm{bc}) \mathrm{ab}$ & $\mathrm{S}(10.0 \pm 2.2 \mathrm{~b}) \mathrm{a}$ \\
\hline
\end{tabular}

Explant regeneration response after $10 \mathrm{~d}$ : S, shoot induction; R, root induction; C, callus induction; N, no response. Number of elongated shoots after $30 \mathrm{~d}$ $($ mean $\pm \mathrm{SD})$ given in parentheses. Values followed by the same letters within parentheses in a column are not significantly different $(P>0.05)$. Values followed by same letters in a row (outside parentheses) are not significantly different $(P>0.05)$.
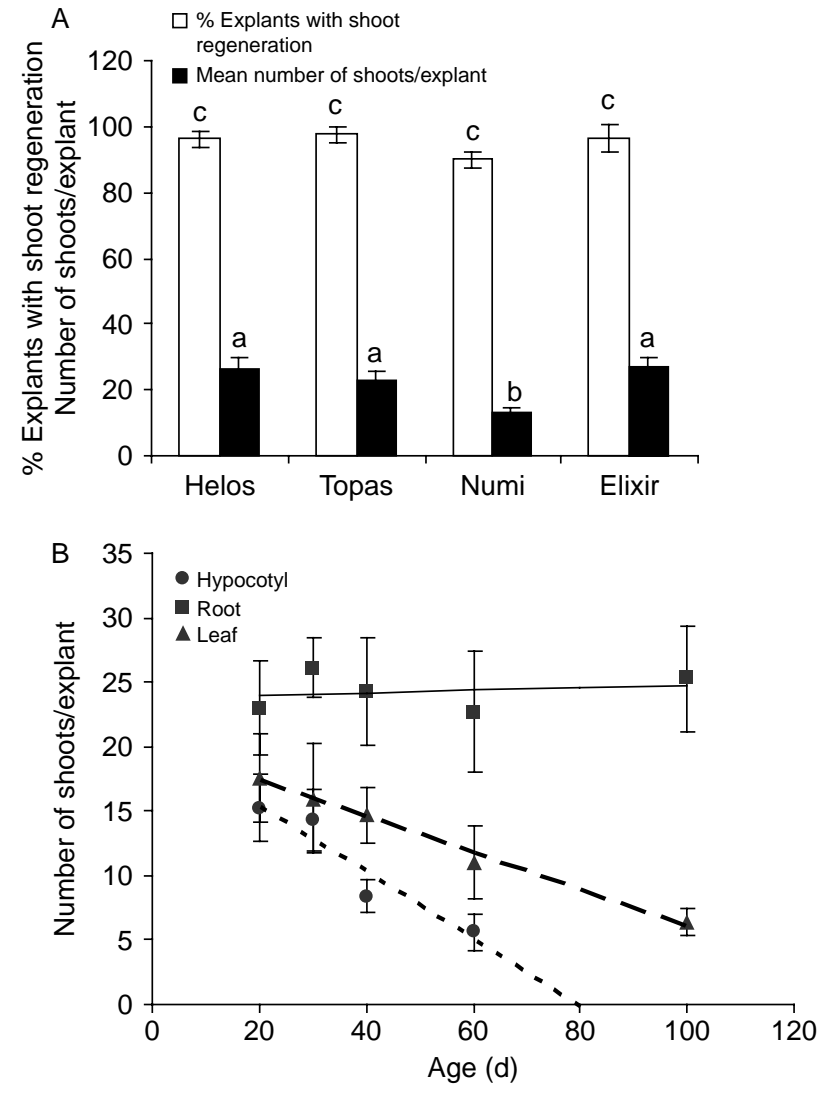

was adjusted to 5.8 with $0.1 \mathrm{M} \mathrm{NaOH}$ or $0.1 \mathrm{M} \mathrm{HCl}$ before autoclaving at $1.0 \mathrm{~kg} \mathrm{~cm}^{-2}$ for $15 \mathrm{~min}$. Filter-sterilized IAA ( $\mathrm{pH} 5.8$ ) was included in the medium after autoclaving when necessary. Culture plates containing $25 \mathrm{ml}$ medium were inoculated with 5-10 explants, sealed with parafilm and incubated at 16-h photoperiod under fluorescent bulbs (Fluora, München, Germany) at the light intensity of $25 \mu \mathrm{mol} \mathrm{s}^{-1} \mathrm{~m}^{-2}$ at $25^{\circ} \mathrm{C}$. To study the effect of explant orientation on regeneration, leaf explants were placed on the media with either their abaxial or their adaxial side touching the medium. The effect of seedling age on regeneration was studied by culturing explants from 20-, 30-, 40-, 60-, and 100-d-old seedlings in M18 (Table 1).

The effect of genotypes on regeneration was studied by culturing leaf, root, and hypocotyl explants from other three genotypes (Topas, Elixir, and Numi) in various media (e.g. M8, M12, M15, and M18; Table 1).

Plantlet formation and hardening. All the explants with or without shoot initials were subcultured once to fresh media within $15 \mathrm{~d}$ of culture initiation. The second subculture was performed onto MS basal medium (M1; Table 1). Elongated shoots $(3-5 \mathrm{~cm})$ were excised from the explant and transferred to baby food jars (Sigma) containing $50 \mathrm{ml}$ of half-strength MS media supplemented with different concentrations of indole-3-butyric acid (IBA; 0.0, 0.49, 2.46, and $4.9 \mu M$ ) for rooting. For hardening, culture bottles containing rooted plants were filled with sterile distilled water and incubated

FIG. 1. Shoot production in St John's wort root segments from different genotypes on MS medium containing $2.2 \mu M$ BA and $5.7 \mu M$ IAA. $A$, Effect of genotypes on regeneration; i.e. percentage of explants that regenerated shoots, along with shoots/explant, values represented in mean $\pm \mathrm{SE}$; bars indicated with similar letters are not significantly different $(P>0.05)$. $B$, Effect of the age of the explants on shoot regeneration; values are the means of three independent experiments and vertical bars indicate $95 \%$ confidence level to the average. Results show that the age of leaf and hypocotyl, but not root, explants had a significant negative correlation with shoot regeneration. The equations of the regression analysis and the respective $r^{2}$ are as follows: $y=0.0091 x+23.031 ; r^{2}=0.0385$ for root, $y=-0.1413 x+20.203$; $r^{2}=0.9912$ for leaf and $y=-0.2586 x+20.571 ; r^{2}=0.9086$ for hypocotyl explants. 

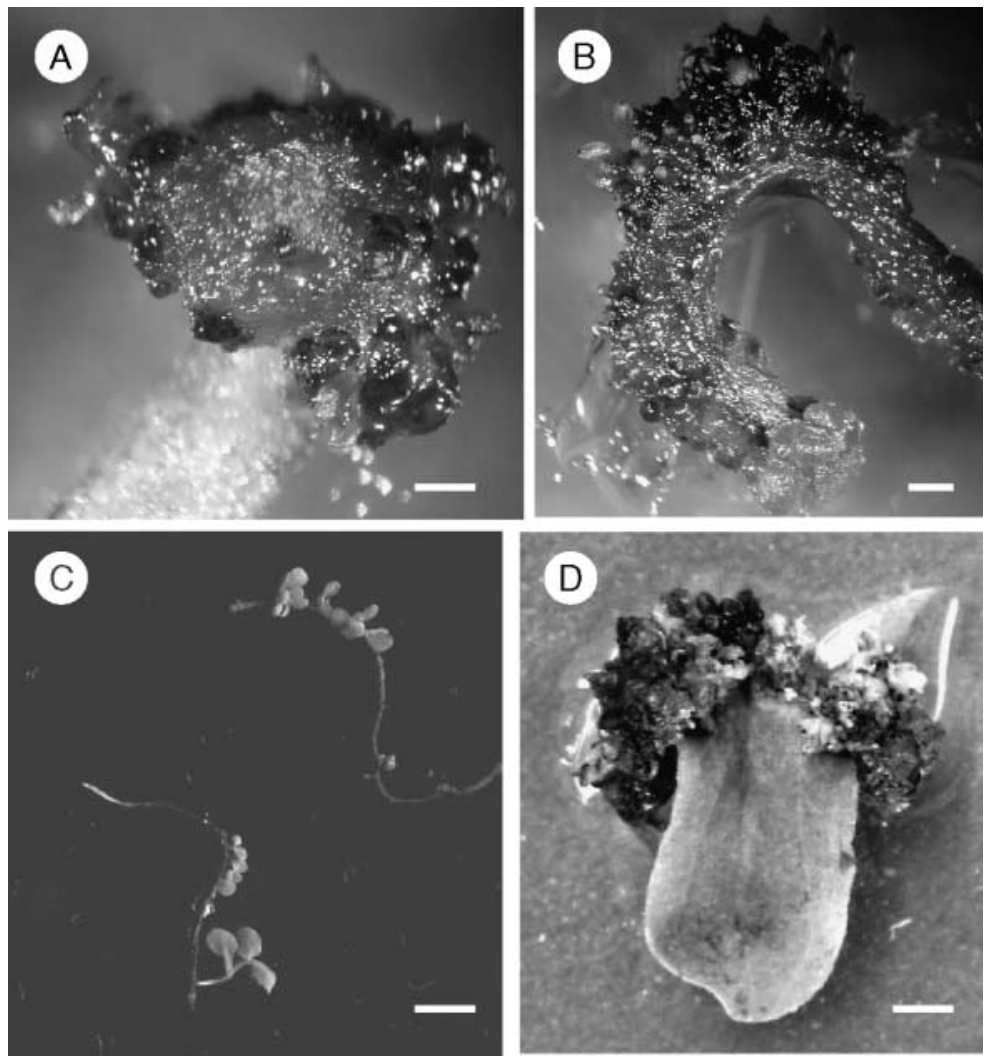

FIG. 2. Regeneration of shoot buds from St John's wort cv. Helos explants: $A$, shoot initiation from the cut end of root segment ( $b a r=0.5 \mathrm{~mm}) ; B$, shoot bud initiation from the sub-epidermal layers of root segment surface $(b a r=0.5 \mathrm{~mm}) ; C$, root segment with shoots developed on basal medium $($ bar $=5.0 \mathrm{~mm}) ; D$, leaf explant showing shoot regeneration only from the cut end $($ bar $=0.5 \mathrm{~mm})$.

at room temperature $\left(26^{\circ} \mathrm{C}\right)$. After $2 \mathrm{~d}$, the plants were removed from the medium, washed thoroughly in running tap water to remove the traces of rooting medium and planted in JIFFY-7 (Lisbon, Portugal) plant propagation systems, and covered with polyethylene bags. The plants were acclimatized by reducing the humidity through making holes in the polyethylene bags and exposing to sunlight gradually for $1 \mathrm{wk}$. Hardened plants were transferred to garden pots containing soil:compost (1:1), irrigated regularly with tap water and grown in the field.

Histology. Explants taken after different days of culture on M18 (Table 1) were fixed in a fixative consisting of $0.1 \mathrm{M}$ phosphate buffer $\mathrm{pH}$ 7.4, $4 \%(\mathrm{v} / \mathrm{v})$ formaldehyde, $10 \%(\mathrm{v} / \mathrm{v})$ dimethyl sulfoxide, and $1 \%(\mathrm{v} / \mathrm{v})$ Tween 20. Tissue blocks were made using Cryogel by freezing in a paper boat. Sections $20 \mu \mathrm{m}$ thick were taken in a cryostat (CryoJane ${ }^{\circledR}$, Instrumedics, Hackensack, NJ, USA) at $-22^{\circ} \mathrm{C}$ and sectioned ribbons were attached to glass slides. The slides were rinsed with water to remove the Cryogel ${ }^{\circledR}$ coat and stained with $1 \%(\mathrm{w} / \mathrm{v})$ safranin for 2 min. After removing excess stain by passing through an ethanol gradient, the slides were mounted in $\mathrm{DPX}^{\circledR}$ (BDH Chemicals, Poole, UK) and viewed under a light microscope (Leica Microsystems, Buckinghamshire, UK) equipped for photomicrography.

Scanning electron microscopy (SEM). Cultured explants were fixed in $2.5 \%(\mathrm{v} / \mathrm{v})$ buffered gluteraldehyde $(0.2 \mathrm{M}$ phosphate buffer, $\mathrm{pH} 7.0)$ and dehydrated in ethanol series $(25,50,70,80,95$, and $100 \% \times 2)$ for $30 \mathrm{~min}$ each. The dehydrated materials were dried using hexamethyldisilizane (Sigma, Barcelona, Spain) and coated with gold under vacuum, using a Polaron SC-502 (Fisons Instruments, Loughborough, UK). Coated materials were viewed with a Leica/Cambridge S-360 SEM at $20 \mathrm{kV}$ and photographed.

Statistical analysis. All the treatments contained at least 30 samples representing three independent replications were analyzed statistically. The effects of PGR combinations, genotypes, and explant types on regeneration were analyzed by Kruskal-Wallis test (one-way ANOVA) followed by Dunn's multiple comparison test. The influence of the age of the explants on regeneration was studied by regression analysis. Statistical analyses were performed using GraphPad Prism version 4.00 for Windows (GraphPad Software, San Diego, CA, USA).

\section{Results and Discussion}

PGR combinations in the medium affected plant regeneration. Tissue developments from the explants cultured on different media after $10 \mathrm{~d}$ are given in Table 1 . Shoot regeneration was faster in medium containing low concentrations of BA either with or without IAA. In contrast, high levels of BA $(8.8 \mu M)$ delayed the production of shoot buds and often resulted in the formation of callus or diminutive red-shoot buds irrespective of genotype. Collectively, higher shoot regeneration and elongation frequencies were observed from cultures initiated on M18 than other media tested. Hence, the medium supplemented with $2.2 \mu M$ BA and $5.7 \mu M$ IAA (M18) is considered optimal in the present study. In M15, all explant types produced callus irrespective of their genotype. The presence of IAA alone in the medium (M6, M11, and M16) either resulted in root proliferation or no response.

Generally, the requirement for shoot regeneration is a high cytokinin/auxin ratio in most species. However, we obtained the best results with St John's wort shoot regeneration in a low cytokinin/auxin ratio (0.5, e.g. M18). Similar requirements for plant regeneration have been reported earlier (Pasqua et al., 2003). Our results also suggest that for callus induction and subsequent regeneration, $H$. perforatum needs a high cytokinin/auxin ratio (3.0, e.g. M15). Even though a delayed regeneration response was 

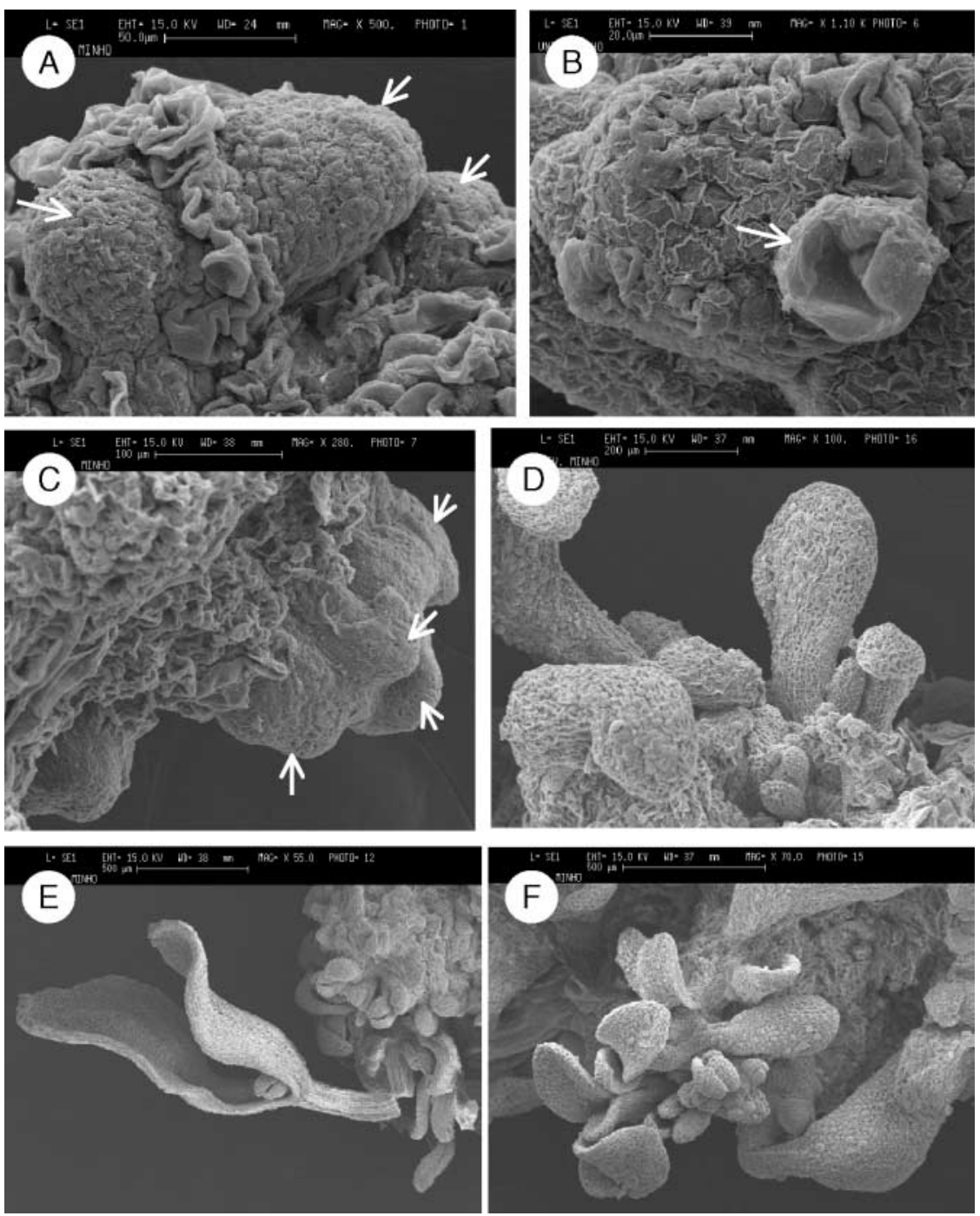

FIG. 3. Electron micrographs showing plant regeneration from root segment explants of St John's wort cv. Helos cultured on M18. $A$, Electron micrograph of root segments cultured for $5 \mathrm{~d}$ showing globular structures (arrow); $B$, electron micrograph of root segments cultured for $8 \mathrm{~d}$ showing secondary globular structure (arrow); $C$, electron micrograph showing the development of primordial leaves (arrow) after $12 \mathrm{~d}$ of culture initiation; $D$, electron micrograph showing shoot buds after $20 \mathrm{~d} ; E$, shoot buds with well-developed cotyledonary leaves; $F$, developed shoots after $25 \mathrm{~d}$.

noticed in Numi, there was no significant difference in the percentage of regeneration and number of shoots/explants between the tested genotypes (Fig. 1A, $P>0.05$ ).

Genotype-independent regeneration is explant type-dependent. The explant type (hypocotyl, leaf, or root) had a significant effect on the regeneration of shoots $(P<0.05$, Table 1$)$. Similar variation in the regeneration frequency of shoots based on explant types on the same TDZ concentration was also reported previously in $H$. perforatum (Zobayed and Saxena, 2003). The PGR combination for optimal regeneration in $H$. perforatum varied with the explant type in the present study as reported in other species (Nikam and Shitole, 1999; Dhar and Joshi, 2005). In the results reported here for $H$. perforatum, the regeneration response is clearly a plant growth regulator-driven explant-dependent phenomenon. Since there has been no difference in the percentage and pattern of regeneration between tested genotypes (Fig. 1A), we consider that the $H$. perforatum regeneration in the present study is genotypeindependent.

Developmental status of the explant affected regeneration. As a general rule, mature explants show poor morphogenetic potential in different species (Walender, 1988; Yepes and Aldwinckle, 1994; Dhar and Joshi, 2005). In our observations with H. perforatum, the age of the explant source also negatively affected the regeneration potential of leaf and hypocotyl explants $(P<0.05)$. In contrast, age did not affect the morphogenetic potential of root segment explants (Fig. 1B). Age-independent regeneration of root segments might be due to the high metabolic activity and faster cell division of roots due to continuous meristematic activity nearer to the root tip.

Orientation of leaf explants on the medium also had a distinct effect on regeneration. While leaves with their adaxial side touching the medium exhibited high frequencies of regeneration, leaves with the opposite surface contacting the medium failed to show any response. 

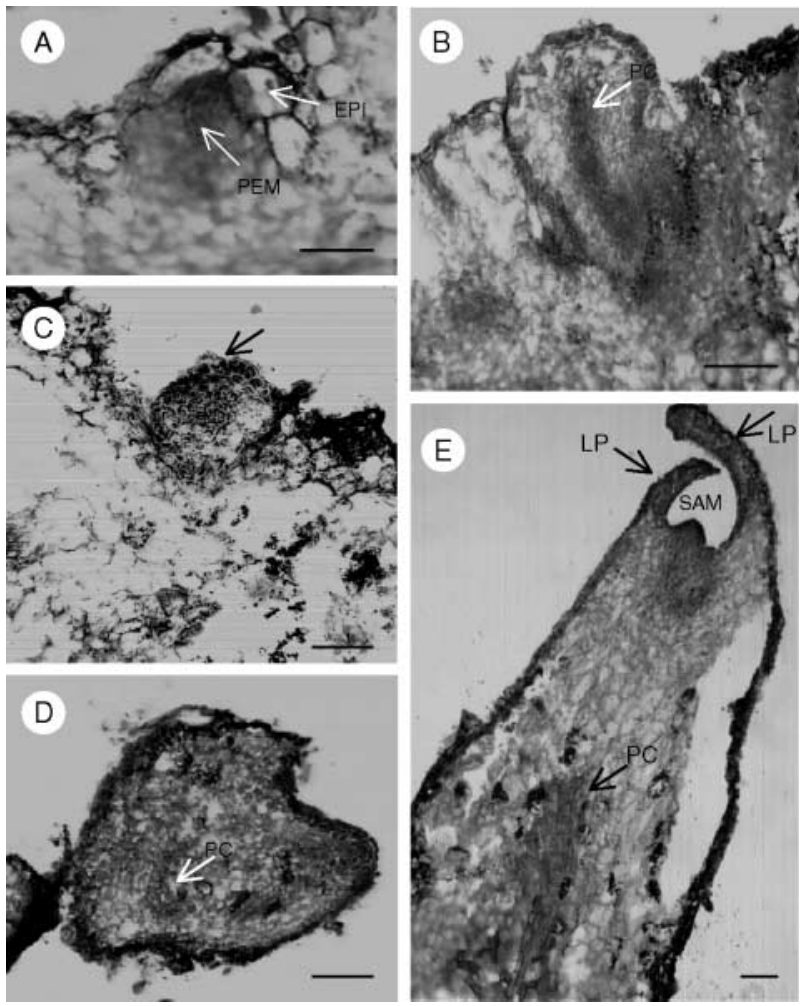

FIG. 4. Histological observations of plant regeneration from root segments of St John's wort cv. Helos cultured on M18: A, formation of proembryonic mass (PEM) by mitotic divisions in the sub-epidermal cells followed by epidermal (EPI) cell expansion (bar $=100 \mu \mathrm{m}) ; B$, protrusion of a globular structure with gradual establishment of polarity and procambium $(\mathrm{PC})($ bar $=100 \mu \mathrm{m}) ; C$, an early globular-stage embryo without procambium ( $b a r=100 \mu \mathrm{m}) ; D$, heart-shaped embryo showing gradual establishment of polarity associated with the differentiation of procambial cell $(\mathrm{PC})$ layer $(b a r=100 \mu \mathrm{m}) ; E$, cotyledon-stage embryo with distinct procambial cell $(\mathrm{PC})$ layer, distinct shoot apical meristem (SAM), and leaf primordia (LP) $($ bar $=100 \mu \mathrm{m})$.

Root segments are ideal explants for regeneration. Among the explant types, root segments quickly responded to the media and produced the highest frequency of shoot buds in all the tested genotypes. On most induction media, the root explants swelled to approximately three times their original size within a week of their inoculation. Adventitious buds or shoots were formed as early as $8 \mathrm{~d}$ after plating directly from the cut ends (Fig. 2A). In most root segments, the outer layer ruptured and subsequent formation of characteristic red-shoot buds from the sub-epidermal layer was noticed (Fig. 2B). Such expansion and rupture of the outer layer were not observed in hypocotyl and leaf explants. Twelve days following culture initiation, clumps of shoot buds containing leaves with well-developed dark glands were noted in the root explants. Low-frequency plant regeneration from root segments could be achieved on medium without supplementation of PGRs (Fig. 2C). This might be due to the influence of the internal cytokinin synthesis in the roots. In contrast, hypocotyls and leaves did not produce any shoots on basal medium and their regeneration response was restricted to their cut ends when incubated on regeneration media (Fig. 2D).

The high-shoot regeneration capability of $H$. perforatum root segments is supported by a previous observation with the genotype Anthos (Zobayed and Saxena, 2003). Rupture of the epidermal layer within $1 \mathrm{wk}$ of culture initiation reveals the faster division of sub-epidermal cells than the epidermis (Fig. 2B). Regeneration from root segments is advantageous over other explants, since roots are relatively more susceptible to Agrobacterium (Morton and Browse, 1991; Franklin and Lakshmi Sita, 2003), which would allow for transgenic varieties to be developed for $H$. perforatum.

Pathways of plant regeneration. For simplicity, the pathways of plant regeneration were studied only in root explants cultured on M18. Based on the SEM observations and microtome sections, we observed organogenesis and somatic embryogenesis in a single culture of $H$. perforatum.

Direct regeneration via organogenic globule formation. Observations from SEM photographs and microtome sections of the explant material taken after different days of culture initiation describe the direct shoot regeneration pathway. Globular structures were induced from the explants after $5 \mathrm{~d}$ of culture initiation (Fig. $3 A$ ). Histological observation of these globular structures revealed the presence of cells with dense cytoplasm. Within another $3 \mathrm{~d}$, these structures appeared as individual globules attached to the explant. They displayed a welldefined globular shape without vascular connection to the original tissue. Since these structures were not surrounded by callus, we concluded that they were originating from the sub-epidermal layers of the explants directly. Similar globular structures were also noticed in the later stages of $H$. perforatum suspension cultures, which resembled raspberry fruit (Vardapetyan et al., 2000).

Secondary proliferation of globular structures was prevalent in explants cultured for $12 \mathrm{~d}$ (Fig. 3B, arrow) and resembled the proliferation of secondary somatic embryogenesis reported in 

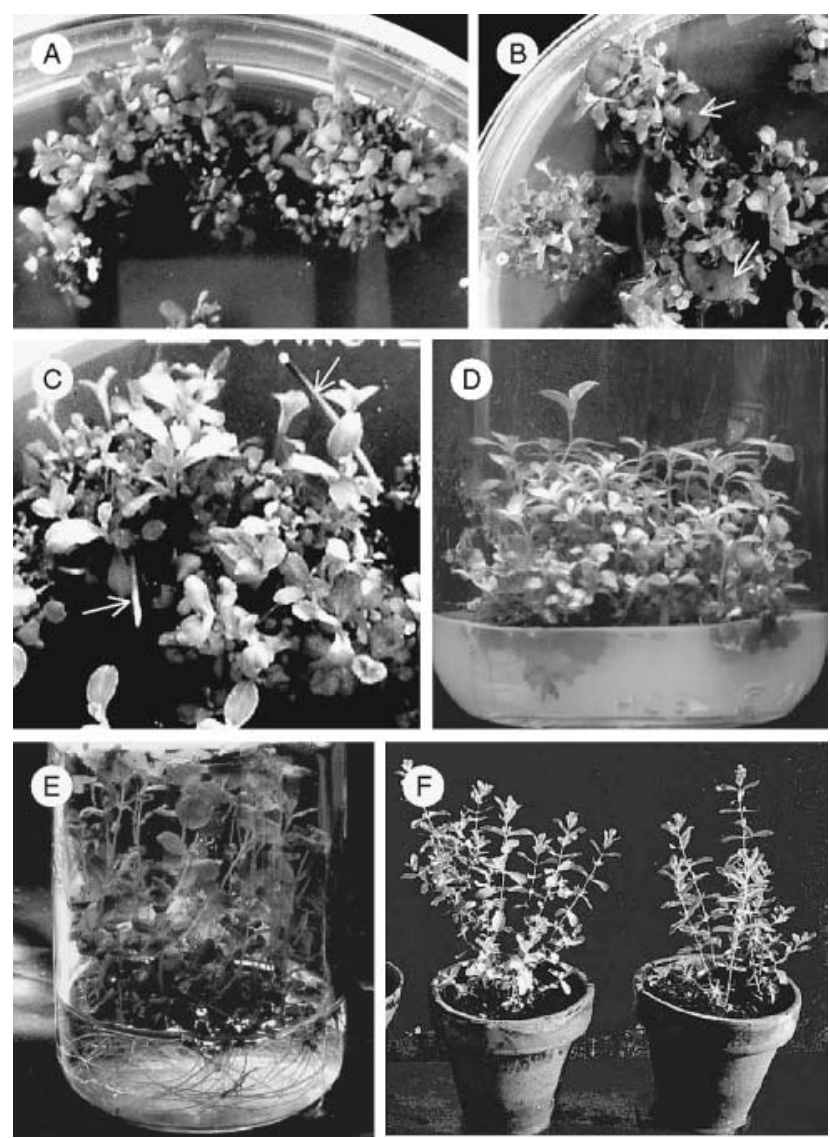

FIG. 5. Later stages of plant regeneration and field establishment of St John's wort cv. Helos; A root segments cultured on M18 showing clumps of shoots after $30 \mathrm{~d}$ of culture initiation; $B$, leaf explants showing shoot regeneration (arrows indicate explant); $C$, hypocotyl explants showing shoot regeneration (arrow indicates explant); $D$, elongation of shoots from a single root segment on basal MS medium after $14 \mathrm{~d}$ of subculture; $E$, a large number of plants rooted in liquid half-strength MS medium containing $0.49 \mu M$ IBA; $F$, vigorously growing plants established in the pot in field conditions, after hardening.

other plant species (Little et al., 2000; Li et al., 2002). Differentiation of the globular structures and the appearance of shoot apex and primordial leaves (Fig. 3C) were observed in explants after $12 \mathrm{~d}$ of culture. The appearance of numerous tiny shoot buds (Fig. 3D) containing well-developed cotyledonary leaves (Fig. 3E) was noticed after $20 \mathrm{~d}$. These shoot buds developed into shoots within another $5 \mathrm{~d}$ (Fig. $3 F$ ). All the above observations collectively suggest that the primary or secondary globular structures can lead to plantlet formation via organogenesis. As the plantlets could not be separated from the explant, we confirmed that the pathway is organogenic. In contrast, the distinctive feature of somatic embryos is the separation of embryo from the explant leading to the formation of a plantlet.

Somatic embryogenesis. To demonstrate the occurrence of somatic embryos, histological sections of the explants were examined. Sections of root segments revealed the rapid mitotic divisions in sub-epidermal cells followed by the expansion of epidermal cells (Fig. 4A). Expansion was restricted to specific epidermal cells that bordered the actively dividing sub-epidermal cells. Active division of the sub-epidermal cells resulted in the formation of proembryonic masses (PEMs). These PEMs are a group of small, deeply stained, and fast-dividing cells gradually protruding outward (Fig. 4B). Protuberances gradually established polarity along with the development of a distinguishable procambial cell (PC) layer. Development of PCs in this stage suggests that these structures can directly develop into shoots. These might be the globular structures observed in the organogenic pathway (Fig. 3A) that developed into shoots later. However, many of the protrusions appeared as a globular clump of deeply stained meristematic cells without procambium and epidermis (Fig. 4C) and might be the early globular-stage somatic embryo.

Heart-shaped somatic embryos present in the culture after $12 \mathrm{~d}$ must have developed from globular embryos. Heart-shaped embryos showed gradual establishment of polarity associated with differentiation of PC layer (Fig. 4D). The cotyledon-stage embryos with well-developed shoot apex and leaves were found in the explants taken after $20 \mathrm{~d}$ of culture initiation (Fig. $4 E$ ). In spite of the presence of defined embryogenic stages, no seedlings germinated from any somatic embryos in the initial culture medium or on MS basal medium were noted. This suggests that additional parameters need to be studied in detail to achieve embryo conversion.

Shoot elongation, rooting, and hardening. After $30 \mathrm{~d}$ of culture, all the explants appeared as clumps of well-developed shoots on their initial regeneration media. Numerous shoots were developing from the root segments almost across the entire surfaces (Fig. 5A). 
Conversely, in leaf and hypocotyl explants, the shoot regeneration was restricted to the cut ends having contact with the medium (Fig. $5 B, C$, arrows indicate explants). Shoot multiplication and the number of elongated shoots greatly increased when the explants were subcultured onto basal medium (Fig. 5D). Shoot elongation was also faster on basal medium than on media supplemented with PGRs. Hence, the second subculture was made to basal medium for all the explants, irrespective of their genotype and initial regeneration media.

Because of the continued shoot multiplication on MS basal medium, numerous shoot buds and shoots ranging between 0.5 and $5.0 \mathrm{~cm}$ height were noted. For the convenience of counting, only shoots that reached at least $3 \mathrm{~cm}$ long were considered for data analyses. Mean number of elongated shoots $(3-5 \mathrm{~cm})$ on MS basal medium after $14 \mathrm{~d}$ of subculture is given in Table 1 . The maximum number of elongated shoots per roots, leaves, and hypocotyls was achieved from explants cultured on M13, M3, and M18, respectively.

Transfer of excised shoots to half-strength MS medium with or without IBA resulted in root induction within a week. In the presence of increasing IBA concentration, the length of roots produced on shoots was reduced while root number and thickness were increased. Medium containing $0.49 \mu M$ IBA was found to be optimal, which induced a mean of $6.6 \pm 3.7$ healthy roots per shoot. Large-scale rooting of shoots was possible using liquid medium with optimal IBA concentration by taking advantage of the floating characteristics of $\mathrm{St}$ John's wort shoots on a liquid medium (Fig. $5 E$ ). When transferred to field conditions, those plants produced many side shoots within $30 \mathrm{~d}$ and grew vigorously thereafter (Fig. $5 F$ ).

In conclusion, a genotype-independent regeneration protocol for $H$. perforatum was defined. Numerous phenotypically normal plants can be regenerated within a short period from different genotypes based on our procedure. Regeneration of H. perforatum can occur by both embryogenesis and organogenesis. Meristematic cells formed from the sub-epidermal layer developed into two functionally different globular structures simultaneously. The globular structures attached to the explant developed into shoots, and the others detached from the explant underwent embryogenesis. Embryogenesis progressed from the globular embryos to the cotyledon stage via heart-shaped and torpedo-stage embryos. Cotyledonary embryos failed to develop into plants as they failed to establish root systems. This genotype-independent regeneration protocol can be used routinely for genetic engineering and commercial propagation of $H$. perforatum.

\section{ACKNOWLeDgments}

This work was supported by Fundação de Ciência e Tecnologia (POCTI/AGR/40 283/2001). G. Franklin is grateful to Fundação de Ciência e Tecnologia for a Postdoctoral Fellowship Grant (SFRH/BPD/17102/2004).

\section{References}

Agostinis, P.; Vantieghem, A.; Merlevede, W.; Peter, A. M. Hypericin in cancer treatment: More light on the way. Int. J. Biochem. Cell Biol. $34: 221-241 ; 2002$

Butterweck, V. Mechanism of action of St John's wort in depression: what is known? CNS Drugs 17:539-562; 2003.

Dhar, U.; Joshi, M. Efficient plant regeneration protocol through callus for Saussurea obvallata (DC.) Edgew. (Asteraceae): effect of explant type, age and plant growth regulators. Plant Cell Rep. 24:195-200; 2005

Dias, A. C. P.; Ferreira, M. F. Production of phenolics by in vitro cultures of Hypericum perforatum: A case study. In: Rauter, A. P.; Araujo, M. E.; Palma, F. B.; Justino, J.; Santos, S. P., eds. Natural products in the new millenium: prospects and industrial application. Dordrecht, The Netherlands: Kluwer Academic Publishers; 2003:367-374.

Dias, A. C. P.; Seabra, R. M.; Andrade, B.; Ferreres, F.; Ferreira, M. F. Xanthone production in calli and suspended cells of Hypericum perforatum. J. Plant Physiol. 158:821-827; 2001.

Franklin, G.; Lakshmi Sita, G. Agrobacterium tumefaciens mediated transformation of eggplant (Solanum melongena L.) using root explants. Plant Cell Rep. 21:549-554; 2003.

Gibson, D.; Sirvent, T. Induction of hypericins and hyperforin in Hypericum perforatum L. in response to biotic and chemical elicitors. Physiol. Mol. Plant Pathol. 60:311-320; 2002.

Kirakosyan, A. B.; Vardapetyan, H. R.; Charchoglyan, A. G. The content of hypericin and pseudohypericin in cell cultures of Hypericum perforatum L. (St. John's wort) and production of hypericin. Russ. J. Plant Physiol. 47:270-273; 2000.

Li, X.; Krasnyanski, S. F.; Korban, S. S. Somatic embryogenesis, secondary somatic embryogenesis, and shoot organogenesis in Rosa. J. Plant Physiol. 159:313-319; 2002

Little, E. L.; Magbanua, Z. V.; Parrot, W. A. A protocol for repetitive somatic embryogenesis from mature peanut epicotyls. Plant Cell Rep. 19:351-357; 2000

Morton, L.; Browse, J. Facile transformation of Arabidopsis. Plant Cell Rep. 10:235-239; 1991

Murashige, T.; Skoog, F. A revised medium for rapid growth and bioassays with tobacco tissue cultures. Physiol. Plant. $15: 473-497 ; 1962$

Murch, S. J.; Choffe, K. L.; Victor, J. M. R.; Slimmon, T. Y.; Krishnaraj, S.; Saxena, P. K. Thidiazuron-induced plant regeneration from hypocotyl cultures of St. John's wort (Hypericum perforatum cv. 'Anthos'). Plant Cell Rep. 19:576-581; 2000.

Nikam, T. D.; Shitole, M. G. In vitro culture of Safflower L. cv. Bhima, initiation, growth and growth optimization and organogenesis. Plant Cell Tiss. Organ Cult. 55:15-22; 1999.

Pasqua, G.; Avato, P.; Monacelli, B.; Santamaria, A. R.; Argentieri, M. P. Metabolites in cell suspension cultures, calli, and in vitro regenerated organs of Hypericum perforatum cv. Topas. Plant Sci. 165:977-982; 2003.

Pretto, F. R.; Santarem, E. R. Callus formation and plant regeneration from Hypericum perforatum leaves. Plant Cell Tiss. Organ Cult. 62:107-113; 2000 .

Schinazi, R. F.; Chu, C. K.; Babu, J. R.; Oswald, B.; Saalman, V.; Cannon, D. L.; Ericksson, B. F. H.; Nasr, M. Anthraquinones as a new class of antiviral agents against human immunodeficiency virus. Antiviral Res. 13:265-272; 1990.

Silva, B. A.; Ferreres, F.; Malva, J. O.; Dias, A. C. P. Phytochemical and antioxidant characterization of Hypericum perforatum alcoholic extracts. Food Chem. 90:157-167; 2005.

Smith, M. A. L.; Kobayashi, H.; Gawienowski, M.; Briskin, D. P. An in vitro approach to investigate chemical synthesis by three herbal plants. Plant Cell Tiss. Organ Cult. 70:105-111; 2002.

Vardapetyan, H. R.; Kirakosyan, A. B.; Charchoglyan, A. G. The kinetic regularities of the globular structures growth in cell cultures of Hypericum perforatum L. Biotechnologia (Moscow) 4:53-58; 2000.

Walender, M. Plant regeneration from leaf and stem seoments of shoots raised in vitro from mature apple trees. J. Plant Physiol. 132:738-744; 1988.

Yepes, L. M.; Aldwinckle, H. S. Factors that affect leaf regeneration efficiency in apple, and the effect of antibiotics in morphogenesis. Plant Cell Tiss. Organ Cult. 37:257-269; 1994.

Zobayed, S. M. A.; Murch, S. J.; Rupasinghe, H. P. V.; Saxena, P. K. In vitro production and chemical characterization of St. John's wort (Hypericum perforatum L. cv. 'New Stem'). Plant Sci. 166:333-340; 2004

Zobayed, S. M. A.; Saxena, P. K. In vitro grown roots: A superior explant for prolific shoot regeneration of St. John's wort (Hypericum perforatum L. cv. 'New Stem') in a temporary immersion bioreactor. Plant Sci. 165:463-470; 2003. 